\title{
A photographic evaluation of factors prevalent in Nepalese smile: A cross-sectional study
}

\author{
Bishal Babu Basnet ${ }^{1, *}$ Indra Kumar Limbu ${ }^{2}$, Prakash Kumar Parajuli ${ }^{3}$ \\ ${ }^{1,2}$ Assistant Professor, ${ }^{3}$ Associate Professor, Dept. of Prosthodontics, College of Dental Surgery, BP Koirala Institute of Health \\ Sciences, Dharan, Nepal
}

*Corresponding Author:

Email: bishal_bpkihs@yahoo.com

\begin{abstract}
Aim: The aim of this study was to find out the prevalence of different characteristics of smile and to determine the level of normalcy based on the above.

Materials and Methods: The standardized digital photographs of 529 participants were collected and transferred to personal computer in which the different characteristics of smile were visually inspected.

Results: Smile with average upper lip position (54\%) straight upper lip curvature in smile (46.9\%), parallel incisal line to upper border of lower lip (51.8\%) and incisal edges of maxillary dentition not touching to lower lip (62.4\%) were most occurring characteristics with statistically significant prevalence of gingival and mucosal smiles amongst females.

Conclusions: The study outlined few most occurring characteristics in smile of Nepalese population. The average upper lip position, straight upper lip curvature and parallel incisal line were some of the most prevalent characteristics in Nepalese smile.
\end{abstract}

Keywords: Smile, Esthetics, Dentition, Nepalese.

\section{Introduction}

Smile is defined as a happy or friendly expression on the face with ends of mouth curving up slightly with display of teeth accompanied by brightening eyes. ${ }^{1,2}$ Smile is considered as a first-rate human interaction due to color contrast present in teeth, gingivae and lips. ${ }^{3}$ The features included in ten commandments of smile are vertical positioning of maxillary incisors at smiling, width-height ratio of incisors, proportionate distribution between maxillary anteriors, no diastema, proper level of gingival margin, intermediate buccal corridor, minimal gingival exposure, minimal midline and tooth angulation, ideal color and anatomical shape and lip volume. ${ }^{3}$ During smile, maxillaries are separated, and a dark space develops between upper and lower teeth, also known as negative space. ${ }^{4}$ Smile is a unique gesture of face because of fine miscellany of lips, teeth and dark spaces creating a harmonious effect. ${ }^{4,5}$ Historically, esthetic treatment was aided by accepted smile design concepts and smile parameters. These specific measurements through smile analysis aid in formation of smile design and such information can be conveyed between dentist, ceramist and patient.

Smile analysis is a cincture of facial esthetics, orofacial esthetics, oral esthetics, dentogingival esthetics and dental esthetics ${ }^{6,7}$ which helps to restore the lost dentition and bring back this unique feature in face by prosthodontic, periodontal, conservative or orthodontic treatment. The cynosure of any such treatment is towards creating a balanced smile rather than an ideal smile. ${ }^{8}$

This cross-sectional descriptive study aimed to find the different types of smile in Nepalese population which may succor the clinicians to design smile for esthetically-indisposed people.

\section{Materials and Methods}

It was a cross-sectional study carried out in the participants from eight districts of Eastern Nepal (Taplejung, Solukhumbu, Pachthar, Sunsari, Ilam, Morang, Dhankuta and Bhojpur). The individual participant was informed about the procedures of photography with maintenance of confidentiality and anonymity. The information sheet was provided in local language understandable to the person. The consent form was signed after full comprehension by the participant. The ethical approval of this study was obtained from institutional review committee of BP Koirala Institute of Health Sciences (385/073/074-IRC). The districts were selected by lottery method from among 16 districts. Sample size for each district was calculated through population proportionate sampling. The individual participant recruitment was done by convenient sampling. Participants with intact maxillary teeth without any history of orthodontic, prosthodontic and restorative treatment above 18 years of age were included. Those with significant facial deformities were excluded.

To elucidate the complexity of classification of ethnic groups of Nepal various literature were sought which divided ethnicity of Nepal into one of the the three ethnic groups (Indo-Nepalese, Tibeto-Nepalese and Newars). ${ }^{9,10}$

Frontal photographs were taken with D3400 camera with Nikon lens $18-55 \mathrm{~mm}$ (Nikon Corp. Japan) when subject's head was in upright position as she or he smiled with social smile (Fig. 1 and 2). The photographs were made in neutral background and in 90 degrees to the participant's face. 
The photographs were copied to the computer MacBook Pro (Apple Inc. California, USA, 2016) with LCD screen of 1280X800 resolution and 32-bit color. The blurred or distorted images with low quality which could cause difficulty in examination were repudiated. To evaluate the association between different parameters of smile and gender Chi-square test was applied. Level of significance was kept at 0.05 .

Parameters evaluated in this study were upper lip position (classified as high, average and low smile), upper lip curvature (classified as upward, straight or downward), parallelism of maxillary incisal curve with upper border of lower lip (parallel, straight and reverse), relationship of maxillary anterior teeth to lower lip (slightly covered, touching and not touching) and number of teeth exposed. High smile refers to the display of total cervico-incisal length of the maxillary anterior teeth and contiguous band of gingivae, average smile reveals $75-100 \%$ of maxillary anterior teeth and low smile is display of less than $75 \%$ of maxillary anterior teeth. Upward curvature means the corner of mouth is higher than the center of lower border of upper lip. When the corner of mouth and center of lower border of lip are on a straight line, it is called 'straight', and downward means corner of mouth is lower than center of lower border of upper lip.

Parallelism was studied whether incisal edge of maxillary anterior teeth are parallel to upper border of lower lip, or in straight line or in reverse relation. In smile, we also studied whether lower lip touches, does not touch or even covers the incisal edges of maxillary anterior teeth. Number of teeth exposed include whether canines, premolars or molars are seen or not during smile. In assessing the deviation factors (Fig. 2), we checked for presence of midline diastema, multiple gaps, interincisal gap, and canting of upper lip during smile.

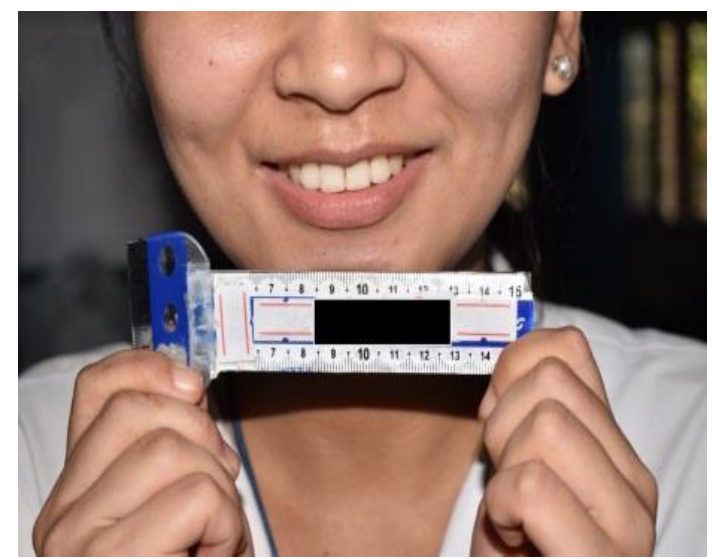

Fig. 1: An example of photograph of the participant during the posed smile, shaded part contains the code number, age and gender of the participant

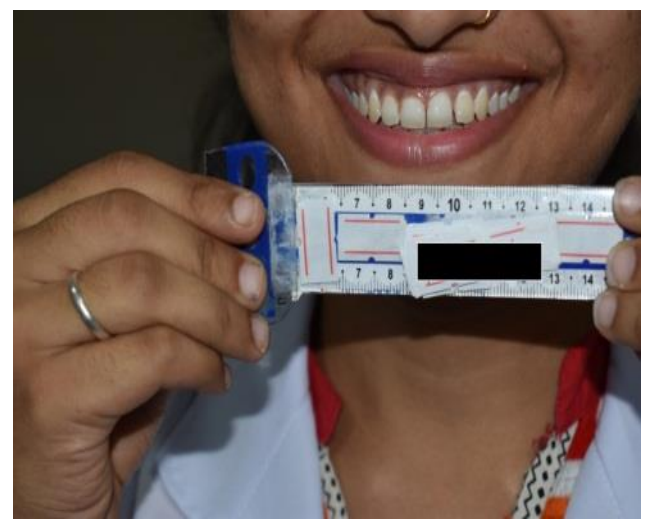

Fig. 2: An example of smile with high lip line and multiple gaps between teeth

\section{Results}

After excluding the unsuitable images, final sample consisted of 529 photographs of volunteers (mean age $=25.68$ years, $\mathrm{SD}=8.01$ ) among them $56.7 \%$ were males and $43.3 \%$ were females. The average smile was found in $54 \%$ of the participants (Table 1). The males and females have similar distribution of average smile. Notably, high smile was found in $19.21 \%$ of female and only $10 \%$ of males whereas low smile was present in about $36 \%$ males and only $26 \%$ females. Chi-square test showed this to be statistically significant $(\mathrm{p}<0.05)$.

Occurrence of straight upper lip curvature was more common (approximately $47 \%$ in both genders) followed by downward curvature $(41.48 \%$ female and $36.33 \%$ male). The least type was upward with $11.35 \%$ in females, $17 \%$ in males and $14.6 \%$ in overall studied population. This was not statistically significant in terms of gender.

Sixty-two percent of total sample had their maxillary teeth not touching the lower lip in smile photographs. The presence of this feature accounted for $66 \%$ males and $57.64 \%$ females (Table 1). Tooth type of smile was most prevalent $(48.39 \%)$ followed by papillary smile (37.43\%). More number of females had papillary $(38.43 \%)$ but more number of males had tooth type of smile (53.33\%). The difference was found to be statistically significant $(\mathrm{p}<0.05)$.

In assessing teeth displayed, most had display of teeth up to first premolars bilaterally (approximately $32 \%$ in each of overall sample, males and females); very few ( $7.56 \%$ of total sample) had less than six teeth displayed. An additional category of asymmetric display of teeth is added in this study which means the number of teeth displayed on right side is less or more than that on the left side. The prevalence of such characteristics was $19.47 \%$ of total sample (Table 2).

Fig. 3 depicts some of the deviation from ideal smile such as presence of multiple gaps (13.8\%) and midline diastema (11\%).

Pertaining to ethnic groups, Indo-Nepalese composed of $71 \%$ of studied sample, average type of smile was highly prevalent in all ethnic groups; viz., 
Indo-Nepalese (55.32\%), Tibeto-Nepalese (46.96\%) and Newars $(63.16 \%)$. Straight curvature of upper lip was observed in $47.67 \%$ Indo-Nepalese, $45.22 \%$ Tibeto-Nepalese and $50 \%$ Newars. However, downward curvature was also prevalent $(42.61 \%$ in Tibeto-Nepalese and $39.47 \%$ in Newars, $37.23 \%$ in
Indo-Nepalese) considerably. Most found characteristic in regards to relation of maxillary teeth to lower lip was 'not touching' type with $61.97 \%, 67.83 \%$ and $50 \%$ prevalence in Indo-Nepalese, Tibeto-Nepalese and Newars respectively.

Table 1: Gender wise comparison of different characteristics of smile $(n=529)$

\begin{tabular}{|c|c|c|c|c|c|}
\hline \multicolumn{2}{|l|}{ Characteristics } & $\begin{array}{l}\text { Female }(\%) \\
n=229\end{array}$ & $\begin{array}{l}\text { Male (\%) } \\
\mathrm{n}=300\end{array}$ & Total $(\%)$ & $\begin{array}{l}\text { Chi-square } \\
\text { statistics }\end{array}$ \\
\hline \multirow{3}{*}{$\begin{array}{ll}\text { Upper } & \text { lip } \\
\text { position } & \end{array}$} & High smile & $44(19.21)$ & $30(10.0)$ & $74(14)$ & \multirow{3}{*}{$\begin{array}{c}12.063 \\
(p=0.002)^{*}\end{array}$} \\
\hline & Average smile & $125(54.59)$ & $161(53.67)$ & $286(54.1)$ & \\
\hline & Low smile & $60(26.2)$ & $109(36.33)$ & $169(31.9)$ & \\
\hline \multirow{3}{*}{$\begin{array}{ll}\text { Upper } & \text { lip } \\
\text { curvature } & \end{array}$} & Upward & $26(11.35)$ & $51(17.0)$ & $77(14.6)$ & \multirow{3}{*}{$\begin{array}{c}3.810 \\
(p=0.149)\end{array}$} \\
\hline & Straight & $108(47.16)$ & $140(46.67)$ & $248(46.9)$ & \\
\hline & Downward & $95(41.48)$ & $109(36.33)$ & $204(38.6)$ & \\
\hline \multirow{4}{*}{$\begin{array}{l}\text { Parallelism of } \\
\text { maxillary teeth }\end{array}$} & Parallel & $128(55.9)$ & $146(48.67)$ & $274(51.8)$ & \multirow{4}{*}{$\begin{array}{c}4.939 \\
(p=0.176)\end{array}$} \\
\hline & Straight & 45 (19.65) & $66(22.0)$ & $111(21)$ & \\
\hline & Reverse & $18(7.86)$ & $39(13.0)$ & $57(10.8)$ & \\
\hline & Inaccessible & $38(16.59)$ & $49(16.33)$ & $87(16.4)$ & \\
\hline \multirow{3}{*}{$\begin{array}{l}\text { Relationship of } \\
\text { maxillary teeth } \\
\text { to lower lip }\end{array}$} & $\begin{array}{l}\text { Slightly } \\
\text { covered }\end{array}$ & $41(17.9)$ & $50(16.67)$ & $91(17.2)$ & \multirow[t]{3}{*}{$\begin{array}{c}4.771 \\
(p=0.092)\end{array}$} \\
\hline & Touching & $56(24.45)$ & $52(17.33)$ & $108(20.4)$ & \\
\hline & Not touching & $132(57.64)$ & $198(66.0)$ & $330(62.4)$ & \\
\hline \multirow{4}{*}{$\begin{array}{l}\text { Smile display } \\
\text { type }\end{array}$} & Tooth smile & $96(41.92)$ & $160(53.33)$ & $256(48.39)$ & \multirow{4}{*}{$\begin{array}{c}16.042 \\
(p=0.003) *\end{array}$} \\
\hline & Papillary smile & $88(38.43)$ & $110(36.67)$ & $198(37.43)$ & \\
\hline & Gingival smile & $35(15.28)$ & $27(9.0)$ & $62(11.72)$ & \\
\hline & Mucosal smile & $10(4.37)$ & $3(1.0)$ & $13(2.46)$ & \\
\hline
\end{tabular}

$* \mathrm{p}<0.05$ statistically significant

Table 2: Gender-wise comparison of teeth displayed in the smile $(n=529)$

\begin{tabular}{|c|c|c|c|c|}
\hline Teeth displayed & $\begin{array}{c}\text { Female }(\%) \\
n=229\end{array}$ & $\begin{array}{c}\text { Male (\%) } \\
\mathbf{n}=\mathbf{3 0 0}\end{array}$ & Total & $\begin{array}{c}\text { Chi- } \\
\text { square } \\
\text { statistic }\end{array}$ \\
\hline Less than canine & $15(6.55)$ & $25(8.33)$ & $40(7.56)$ & \multirow{6}{*}{$\begin{array}{c}5.9493 \\
(p=0.311)^{\dagger}\end{array}$} \\
\hline Up to canine & $59(25.76)$ & $78(26)$ & $137(25.9)$ & \\
\hline Up to first premolar & $75(32.75)$ & $98(32.67)$ & 173(32.7) & \\
\hline Up to second premolar & $25(10.92)$ & $42(14.0)$ & $67(12.67)$ & \\
\hline More distal to second premolar & $2(0.87)$ & $7(2.33)$ & $9(1.7)$ & \\
\hline Asymmetrical on right and left side & $53(23.14)$ & $50(16.67)$ & $103(19.47)$ & \\
\hline
\end{tabular}

$\mathrm{p}>0.05$, statistically not significant

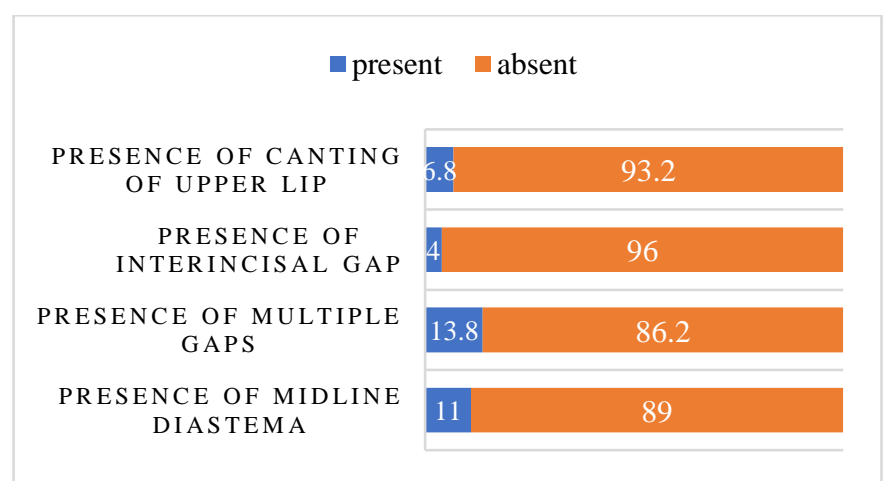

Fig. 3: Percentage of presence of different deviation factors in smile $(n=529)$ 


\section{Discussion}

This study explored the characteristics of Nepalese smile and outlined some deviation factors from ideal smile. This is photographic study done in large-scale population from Eastern Nepal to determine important normalcy factors in smile.

It is important to note that mere beauty of teeth cannot give a cumulative visual impact and micro as well as macroesthetic elements need to be fulfilled for designing a better smile. ${ }^{11}$ Owing to number of constraints, present study incipiently took oral esthetic components of smile.

In current study, average smile was more prevalent than high smile and low smile. This is in agreement with many studies. ${ }^{12-16}$ More number of females (19.21\%) had high smile, the prevalence of smiles revealing a continuous band of gingivae was $15.28 \%$, about $4.37 \%$ even had mucosal type of smile Table 1 . This is also in agreement with many other studies. ${ }^{13,15,17,18}$ In contrast, in a study done on smiling photographs of celebrities, low smile is more prevalent in the females. ${ }^{19}$ Longer height of gingival display in female, in current study may be attributed to smaller teeth in contrast to long occlusal vertical dimension. Comparatively very less difference was observed between dimensions of lower facial height in males and females in Nepalese population by Basnet et al. ${ }^{20}$

The characteristics like, average smile with 75$100 \%$ teeth exposed by upper lip, straight curvature of upper lip, parallel incisal curve line to upper border of lower lip and maxillary incisal line not touching the lower lip were in higher proportion in current study. These were salient features in both males and females. In context to curvature of upper lip, our finding is in agreement with an Indian study. ${ }^{13}$ They also reported reverse relation of incisal curve in males and straight in females in contrast to current study where we found parallel incisal curve in higher proportion. Parallel incisal curve has been reported in many other studies as significant finding in smile. ${ }^{12,14,19,21}$

In a social, posed smile which we utilized for our study the maxillary teeth were not in contact with lower lip in about $62 \%$ participants $(57.64 \%$ females and $66 \%$ males). In the study done by Al-Johany et al. ${ }^{14} 42 \%$ female celebrities have this feature. Others ${ }^{12,13,16,19}$ also reported 'not touching' feature as most prevalent in both genders. In Indian population, who share many anthropometric characters to Nepalese population, have 'touching' relationship in about $41 \%$ of the studied sample. ${ }^{12}$

Maximum number of participants had their eight teeth displayed (up to first premolars bilaterally) in social smile. This is in accordance with studies by Joshi et al. ${ }^{12}$ in an Indian sample and Beom et al. ${ }^{16}$ in a Korean sample. But some studies found exposure up to second premolars ${ }^{19}$ and up to molars ${ }^{13}$ in higher proportion.
Contrary to most of the studies, we outlined the asymmetric exposure as a separate category, in which either left or right side of smile has less number of teeth exposed than on the other side. Overall, $19.47 \%$ (23.14\% female and $16.67 \%$ male) have this kind of lopsided smile.

Presence of midline diastema has contrasting effects on smile, it can be perceived as unattractive for an ideal smile ${ }^{22,23}$ whereas small midline diastema can go unnoticed. ${ }^{24}$ Our study found that $11 \%$ participants had the midline diastema. This entity possesses a significant treatment need from the orthodontic point of view. ${ }^{25}$

Upper lip asymmetry is also a deviation factor from an ideal smile. It creates canting of upper lip thus making the uneven cervico-incisal display of teeth on right and left sides. About $6.8 \%$ of studied population had this deviating factor. In a study by Benson et al. ${ }^{26}$, $8.7 \%$ were reported to have this problem.

The limitations of this study are: We could not utilize the videographic method as suggested in previous studies. ${ }^{15,27-29}$ Only the static smile was evaluated. The photographs covered only lower portion of face thus relationship of smile to interpupillary line, ala-tragus line or upper facial anatomy could not be evaluated. It was limited to only conveniently sampled population whose findings cannot be extrapolated in many other ethnic diversities of Nepal.

\section{Conclusions}

Current study assessed the oral esthetic components of smile, the governing factors of Nepalese smile is reported. Based on position of lip, curvature of upper lip, the parallelism of incisal line to upper edge of lower lip and relationship of incisal edges of maxillary teeth to lower lip, the smile classification was done and prevalence of various types of smile was determined. The average type of smile, with parallel incisal curve and not touching to lower lip was most prevalent type of smile in Nepalese population, however there was considerable occurrence of deviation factors in smile such as midline diastema, canting of upper lip, and multiple gaps between the teeth.

Disclosure: An earlier abridged version of this work was presented in the $40^{\text {th }}$ Asia Pacific Dental Congress on May $8^{\text {th }} 2018$ in Manila, Philippines as oral presentation.

Acknowledgement: The support of Dr Jamal Giri during data collection and editing of manuscript is appreciated. We also thank Dr Ujjwal Gautam, Dr Anuha Gautam, Mr Bharat KC, Mr Anil Poudel, Mr Deepesh Shrestha, Ms Smriti Rai, Ms Rekha Khadka and Ms Puja Basnet for helping to collect photographs from different locations. 


\section{Conflict of Interest: None}

\section{References}

1. Definition of smile, https://www.merriamwebster.com/dictionary/smile (accessed 4 October 2017).

2. Smile meaning in the Cambridge English dictionary. Dictionary.cambridge.org. 2016, http://dictionary.cambridge.org/dictionary/english/smile (accessed 4 December 2016).

3. Machado AW. 10 commandments of smile esthetics. Dent Press J Orthod 2014;19:136-57.

4. Mathews T. The anatomy of a smile. J Prosthet Dent 1978;39:128-34.

5. Levin EI. Dental esthetics and the golden proportion. $J$ Prosthet Dent 1978;40:244-52.

6. McLaren E, Culp L. Smile analysis: the photoshop smile design. J Cosmet dent 2013;29:94-108.

7. Rufencht C. Principles of esthetic integration. 1st ed. Hanover Park (IL): Quintessence Pub., 2000.

8. Janzen EK. A balanced smile--a most important treatment objective. Am J Orthod 1977;72:359-72.

9. Pokharel R. Politics and problematics of the definition and categorization of ethnicity in Nepal. Bodhi: An Interdiscip J 2011;5:318-19. URL:

10. Nepal - Caste and Ethnicity, http://countrystudies.us/nepal/31.htm (accessed 5 October 2017).

11. Morley J, Eubank J. Macroesthetic elements of smile design. JADA 2001;132:39-5.

12. Joshi MN, Joshi NV, Kulkarni AD. Study to evaluate dentofacialractors governing an esthetic smile. Int $J$ Stomatol Res 2014;3:1-6.

13. Meshramkar R, Agrawal R, Pillal Lk., Nadiger RK. A study to evaluate some of the esthetic factors determining attractive smile. Int J ProsthodontRestor Dent 2016;6:316.

14. Al-Johany SS, Alqahtani AS, Alqahtani FY, Alzahrani AH. Evaluation of different esthetic smile criteria. Int $J$ Prosthodont 2011;24:64-70.

15. Liang L-Z, Hu W-J, Zhang Y-L, Chung K-H. Analysis of dynamic smile and upper lip curvature in young Chinese. Int J Oral Sci 2013;5:49-53.

16. Beom S-G, Jung J-H, Kim T-Y, Lee K-E, Dong J-K. A study on the smile of Korean Youth compared with twenty years ago. $J$ Korean AcadProsthodont 2012;50:162-168.

17. Tjan AH, Miller GD. The JG. Some esthetic factors in a smile. J Prosthet Dent 1984;51:24-8.

18. Al-Jabrah O, Al-Shammout R, El-Naji W, AI-Ajarmeh $\mathrm{M}, \mathrm{AI}-\mathrm{Quran} \mathrm{AH}$. Gender differences in the amount of gingival display during smiling using two intraoral dental biometric measurements: Gender Differences in Gingival Display. J Prosthodont 2010;19:286-293.

19. Orce-Romero A, Iglesias-Linares A, Cantillo-Galindo M, Yanez-Vico RM, Mendoza-Mendoza A, Solano-Reina E. Do the smiles of the world's most influential individuals have common parameters? J Oral Rehabil 2013;40:159170.

20. Basnet BB, Singh RK, Parajuli PK, Suwal P, Shrestha P, Baral D. An anthropometric study to evaluate the correlation between the occlusal vertical dimension and length of the thumb. Clin Cosmet Investig Dent 2015;7:33-39.

21. Grover A, Dhawan P, Tandan P, Madhukar P. Analysis of the esthetic components of smile in a section of North Indian population. Int J Prosthodont Restor Dent 2017; 7: 43-47.

22. De Deus Tupinambá Rodrigues C, Magnani R, Machado MSC, Oliveira OB. The Perception of Smile Attractiveness. Angle Orthod 2009;79:634-639.

23. Yousef M, Mokhtar HA, Abuljadayel LW, AI-Ali RM. The perception of smile attractiveness among Saudi population. Clin Cosmet Investig Dent 2015;7:17-23.

24. Kokich VO, Kokich VG, Kiyak HA. Perceptions of dental professionals and laypersons to altered dental esthetics: asymmetric and symmetric situations. Am J Orthod Dentofac Orthop Off Publ Am Assoc Orthod Its Const Soc Am Board Orthod 2006;130:141-51.

25. Huang W, Creath C. The midline diastema: a review of its etiology and treatment. Pediatric Dentistry 1995;17: 171-79.

26. Benson KJ, Laskin DM. Upper lip asymmetry in adults during smiling. J Oral Maxillofac Surg 2001;59:396-98.

27. Sarver DM, Ackerman MB. Dynamic smile visualization and quantification: part 1. Evolution of the concept and dynamic records for smile capture. Am J Orthod Dentofacial Orthop 2003;124:4-12.

28. Sarver DM, Ackerman MB. Dynamic smile visualization and quantification: Part 2. Smile analysis and treatment strategies. Am J Orthod Dentofac Orthop Off Publ Am Assoc Orthod Its Const Soc Am Board Orthod 2003;124:116-27.

29. Siddiqui N, Tandon P, Singh A, Haryani J. Dynamic smile evaluation in different skeletal patterns. Angle Orthod 2016;86:1019-25.

How to cite the article: Basnet BB, Limbu IK, Parajuli PK. A photographic evaluation of factors prevalent in Nepalese smile: A cross-sectional study. J Dent Specialities 2018;6(2):121-125. 